\title{
APPLICATION OF THE CL-SYSTEMS TECHNOLOGY FOR WATER INJECTION WELLS AT AN OIL AND GAS FIELD
}

\section{Liliya Saychenko}

Saint Petersburg Mining University, Oil and Gas Faculty, Department of Development and Operation of Oil and Gas Fields, Saint-Petersburg, Russian Federation

\section{Radharkrishnan Karantharath}

TGT Oilfield Services, Dubai,

United Arab Emirates
$R \partial A D \equiv$

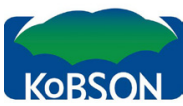

(81) Google

Cite article:

Saychenko, L., Karantharath, R. (2021) APPLICATION OF THE CL-SYSTEMS TECHNOLOGY FOR WATER INJECTION WELLS AT AN OIL AND GAS FIELD, Journal of Applied Engineering Science, 19(3), 848-853, DOI:10.5937/jaes0-31315

Online aceess of full paper is available at: www.engineeringscience.rs/browse-issues 


\title{
APPLICATION OF THE CL-SYSTEMS TECHNOLOGY FOR WATER INJECTION WELLS AT AN OIL AND GAS FIELD
}

\author{
Liliya Saychenko ${ }^{1 *}$, Radharkrishnan Karantharath ${ }^{2}$ \\ ${ }^{1}$ Saint Petersburg Mining University, Oil and Gas Faculty, Department of Development and Operation of Oil \\ and Gas Fields, Saint-Petersburg, Russian Federation \\ ${ }^{2}$ TGT Oilfield Services, Dubai, United Arab Emirates
}

To date, the development of the oil and gas industry can be characterized by a decline in the efficiency of the development of hydrocarbon deposits. High water cut-off is often caused by water breaking through a highly permeable reservoir interval, which often leads to the shutdown of wells due to the unprofitability of their further operation. In this paper, the application of straightening the profile log technology for injection wells of the Muravlenkovsky oil and gas field is justified. In the course of this work, the results of field studies are systematized. The reasons for water breakthrough were determined, and the main ways of filtration of the injected water were identified using tracer surveys. The use of CL-systems technology based on polyacrylamide and chromium acetate is recommended. The forecast of the estimated additional oil produced was made.

Key words: water cut, straightening the profile log, polyacrylamide, chromium acetate

\section{INTRODUCTION}

Currently, the development of the gas and oil producing industry can be characterized by a decline in the production efficiency at a large number of hydrocarbon deposits. Over the past few decades, it is worth mentioning an increased interest of oil companies in the practical application of the advanced high-efficient and cost-effective technologies that ensure the incremental and stable oil production in the hardest geological field conditions $[1,2,3]$. New deposits that have been brought into development are generally composed of low productive, highly heterogeneous and low-permeable reservoirs, oil reserves in them are classified as hard-to-recover with large oil-water and under-gas-cap zones [4, 5, 6]. High water cut is often caused by water breakthrough at the wrong place, this often results in a well shutdown due to the unprofitability of their further operation. Production methods and practices for oil deposits with a conventional waterflooding are likely to be inefficient [7, 8, 9].

Under the current circumstances, only an extensive and widespread introduction of new technologies that significantly increase the efficiency of a conventional waterflooding will enable to reduce the oil production decline rate $[10,11,12]$.

The use of technologies which are aimed at straightening the profile log, redistributing filtration flows and reducing water cut is one of the growth opportunities for performance indicators, especially for mature production fields and fields characterized by a large amount of withdrawn produced water $[13,14,15]$.

Analyzing the reserves depletion at the Muravlenkovskoye oil and gas field, today the remaining reserves can be classified as generally hard-to-recover. As previously mentioned, a problem of a rapid increase in the water cut of the extracted product occurs at the field due to such most common factors as lateral coning in conditions of reservoir heterogeneity when using reservoir pressure maintenance systems. In this case, there is a formation of flushed high-permeability zones, which the water is percolated through to the production wells, and areas with a lower permeability remain unaffected.

All the reasons for water breakthrough are divided into two large groups: those related to the well integrity, and those related to the water encroachment of bed.

1. Casing leak.

2. Behind-the-casing flows from below and overlying formations.

3. The water inflow from a water-flooded reservoir that works in conjunction with other oil reservoirs.

4. Joint water and oil influx from a monolithic stratified oil reservoir.

5. The water inflow the zones of oil-water contact, that is, the inflow from the water-saturated underlying interlayers.

6. The inflows of oil-in-water mixtures directly from oil-saturated reservoirs.

Such water inflows are possible from oil deposits with low oil saturation. The mechanism of this process is insufficiently explored. Low oil saturation of the reservoirs can be easily determined through the GIS system. For effective water isolation, it is necessary to comprehensively examine the water-oil flow features, a change in the phase permeability and water content in the product for the processes considered. At the same time, a need arises for special approaches to reduce or restrain water inflows, since oil production is not possible without water production [18, 19, 20]. 
Frequently, in practice, one is forced to deal with several types of water inflow into the well at once. Often, there can be simultaneous cross flows from the top and bottom horizons, or, along with them, injected water breakthroughs, own water inflows from underlying water-saturated reservoirs, own water inflows from under saturated reservoirs, etc [27, 28, 29].

Below we will consider the case when drowning occurs in highly permeable zones between injection and production wells. The presence of highly permeable zones results in the fact that the displacement front scarcely affects low-permeability oil-saturated zones. For a more complete oil recovery in such cases, it is advisable to take measures to straighten the profile log of injection wells. The creation of hydrodynamic barriers leads to a filtration flows redistribution in the reservoir and an increase in the reservoir sweep efficiency.

\section{Well candidate selection for the profile log straightening}

We conducted an analysis of the Muravlenkovskoye oilfield exploitation system for its BS11 production target. On this evidence, we identified a problematic block 12 with significant oil reserves. Based on the outcomes analysis of field geophysical studies and the chemical composition of the produced water, it was proved that a number of production wells of the Muravlenkovskoye field are flooded with injected water. Analysis of tracer studies testifies to the presence of well-flooded zones in the reservoir. These factors lead to premature flooding of the well and necessitate the work in order to straighten the profile log. The feasibility of the profile log straightening was established at injection well No. 886.

Based on the analysis of field geophysical studies results, as well as the water chemical analysis, it was concluded that flooding of almost all observation producing wells occurs because of injected water, behind-the-casing flows from below and overlying water-saturated formations were not discovered.

Let us estimate the pressure communication between injection well № 886 and the nearest production wells. For this purpose, we will analyze the results of indicator studies.

$1000 \mathrm{~kg}$ of thiocyanate was used as a tracer agent in the form of a dry powder, previously dissolved in $25 \mathrm{~m}^{3}$ of fresh water. Production wells № $843,844,865,939,940$, 2169, 2182, 4137, 4139, 4160, 4177, 4178, 247P were selected as the observation wells.

A total of 553 fluid samples were taken and examined out of 585 planned. The amount of tracer cropped out to the day surface during the entire study period (90 days) was about $29 \%$ relative to the injection mass $(1000 \mathrm{~kg})$.

The indicator was found in the production samples of all producing wells.

Well № 843 is most affected by injection, towards which the total volume of filtered water was $20 \%$ relative to the water produced by it during the study period. Towards the majority of wells № 4139, 4160, 2169, 939. 940, 844 , 4177,2182 , the amount of water filtered in the first 90 days was about $11-16 \%$ of their flow rate. Wells № 4137 , $4178,865(2 \div 6 \%)$ respond to the injection the least.

The bank area at the close of the study period was 15 $358 \mathrm{~m}^{2}$. The front is rather unevenly extended relative to well № 886. It is elongated south-westward (№ 4177, 843,4178 ) by $106 \mathrm{~m}$. The course of well № 844 seems to be the least depleted. About $70 \%$ of the non-recovered tracer proceeds with filtering within the reservoir of interest along the channels with more moderate filtration characteristics, most probably, as part of the displacement frontal advance along the rock matrix.

The first batches of ammonium thiocyanate were recorded in 12-24 hours after the moment of injection for all observation wells, except for № 844,865 , the labeled liquid first approached to its bottomhole in 4-8 days.

Due to the significant remoteness of the observation wells from the injection ones (by an average of $1034 \mathrm{~m}$ ) and the early tracer off-set practically around the entire ringing, the maximum filtration rates were obtained for most courses.

The mean range of the considered parameter amounted to $49 \div 818 \mathrm{~m} /$ day. Meanwhile, the operation of a few channel blocks was determined in the first half of the study for 5-20 days. The permeability values calculated for flow tubes with abnormal-high conductivity $(8 \div 177$ $\mu \mathrm{m}^{2}$ ) indicate that they belong exclusively to flooded-out, depleted zones. The filtration velocity distribution over the study object implies its considerable in homogeneity in conductivity. The results obtained indicate that relatively identical velocity ranges are characterized by different filtration systems for individual wells.

The mean calculated permeability of the identified channels was $4.9 \mu \mathrm{m}^{2}$, which is several hundred-fold higher than the planned level.

Figure 1 (compiled by the authors) shows the established distribution of filtration flows.

Consequently, the results obtained indicate a high-scale development of fissured systems, due to which the hydrodynamic interaction between the injection and recovery zones occurs within the object under study.

As a result of the indicator study carried out in the zone of injection well № 886 of the Muravlenkovskoye field, the following conclusions can be drawn:

1. A good hydrodynamic connection was established between injection well № 886 and all producing wells. The main filtration flows within the area of interest were formed due to the presence of inter layers with abnormal-high conductivity in the productive interval.

2. The mean calculated permeability of the identified channels was $4.9 \mu^{2}$, which is several hundred-fold higher than the planned level of $0.141 \mu^{2}$. 


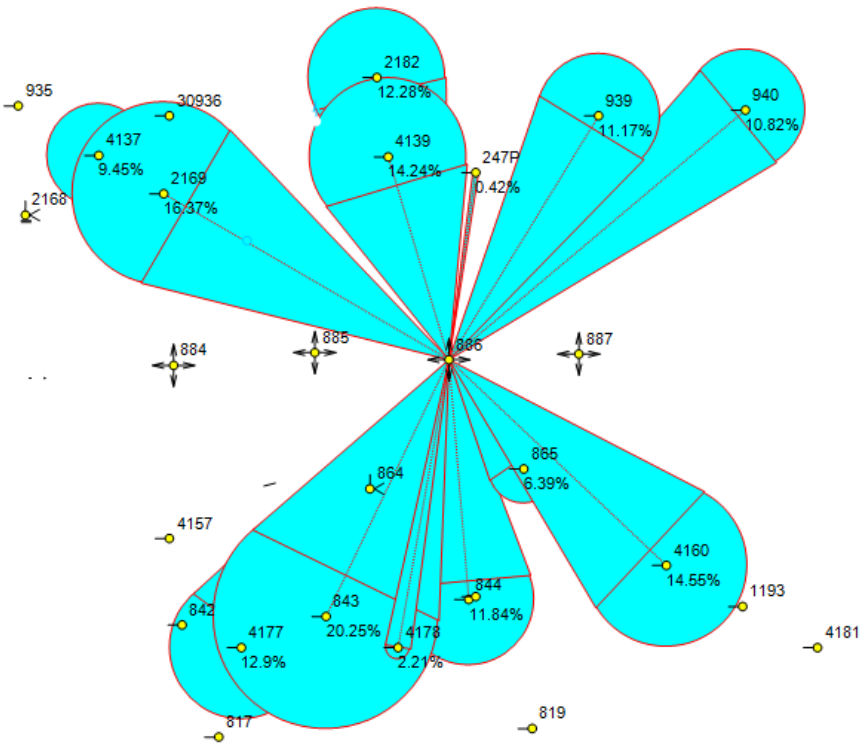

Figure 1: The established distribution of filtration flows within the reservoir of interest

\section{Justification and selection of the profile log straightening technology}

With a cross flow in a stratified heterogeneous reservoir, it is desirable to have a water-insulating composition with a singular mobility. If a cross-flow may occur between the layers, then viscous reagents may enter and block low-permeability oil-saturated zones. The treatment philosophy in this case is to advance a water-insulating composition with a water-like viscosity along a highly permeable interlayer to a distance corresponding to high oil saturation in a less permeable interval with local gel sedimentation. The generated water barrier in the interwell space deflects the injected water into the oil zone with a corresponding increase in the flooding sweep.

Gel treatments are the most effective means to control the water filtration channeling through fractures. The benefits of this technology are determined by the possibility of selective filtration through a highly permeable channel with a composition strengthening as the water infiltrates (gel dehydration), which is difficult to implement when working with dispersed and sediment-forming compositions. The insulating properties of a chromium acetate crosslinked polyacrylamide (PPA) gel depend on injec- tion volume and time, fracture width and length.

Therefore, when conducting an analytical review and generalizing the results of physical-chemical methods implementation at the fields of the Noyabrsk region, we formulated the ways to increase their efficiency: the selection of the best-performing technologies, the cheapest and most technologically advanced reagents, the regional adaptation of technologies.

Table 1 (compiled by the authors) lists the oil growth rate after the application of the profile log straightening methods at the Novogodny field (PJSC Gazpromneft-Noyabrskneftegaz). Based on the tabular indicators, the maximum increase in the oil-production rate is observed after the application of the CL-systems composition (more than 2 times against other treatments). It should be emphasized that injection wells for such treatments were selected with respect to their multiple treatments with standard compositions to straighten the profile log and low response of the surrounding production well stock to the treatment data.

CL-Systems (crosslinked polyacrylamide gel systems) PAA-based compositions with average molecular properties allow for more flexible gelation timing and high filtration selectivity while injecting into a heterogeneous reservoir and, accordingly, have a higher operational benefit when used. In addition, the gel time of the CL-Systems composition heavily relies on temperature [19].

With due regard for the geological and physical characteristics of the BS11 reservoir at the Muravlenkovskoye field (reservoir type, permeability, average water cut, reservoir temperature, etc.), development parameters and screening criteria for the profile log straightening technologies, it may be concluded that the flow deviation technology is most promising one, including injection of crosslinked polymer systems based on a PAA aqueous solution and a CL-Systems crosslinker (chromium acetate).

Thus, the CL-Systems technology based on a PAA aqueous solution with the addition of a crosslinking agent chromium acetate was selected. PAA-based technologies are the most widely used. First of all, unlike other polymer systems, such as hydrolyzed polyacrylonitrile, PAA does not have close restraints on reservoir water salinity and can be effectively applied in Western Siberia with salinity up to $25 \mathrm{~g} / \mathrm{l}$, since it provides reliable isolation of water

Table 1: Increase in the oil-production rate after using profile log straightening physical and chemical methods

\begin{tabular}{|c|c|c|}
\hline Method & Number of wells & Increase in the oil-production rate \\
\hline CL-system & 8 & 2,59 \\
\hline DI+CL system & 10 & 1,12 \\
\hline Hi-vis pill & 30 & 0,86 \\
\hline FDS+Hi-vis pill & 6 & 1,24 \\
\hline WBD+Hi-vis pill & 47 & 1,23 \\
\hline WBD+surfactant+Crosslinked gel+HidrAcid & 5 & 0,77 \\
\hline HidrAcid+surfactant +Crosslinked gel & 44 & 1 \\
\hline Gellant & 47 & 1,19 \\
\hline
\end{tabular}


inflow intervals, while hydrolyzed polyacrylonitrile is effective only when high-salinity water is used. Secondly, we should take note of the stability over time and the presence of the incremental resistance effect which are native to PAA. PAA-based compositions have selective properties due to the preferential molecular absorption in water-saturated intervals. Thirdly, PAA is characterized by a comparably low cost and high technological efficiency. The use of chromium acetate as a crosslinking agent enables to vary the gel time range and rheological properties of the resulting gels within wide limits.

The total production rate of the observation wells amounts to $676,1 \mathrm{t} /$ day as per liquid and $43,9 \mathrm{t} /$ day as per oil. The water cut of the product is $93.03 \%$. It is expected that if the measures for profile log straightening are successful, the permeability in the injection well zone will be amount to $0.141 \mu^{2}$, and the well injectivity will be $177 \mathrm{~m}^{3} /$ day. The working agent will penetrate the unwashed zones and the oil rate will increase. If we assume that all that is injected into injection well № 886 reaches the production wells, then the total daily fluid production rate after successful treatment should come to 574.7 tons / day.

Taking into account such technologies case records at this exploitation target, the mean oil production enhancement should be $10-15 \%$. The average duration of the effect is $7-8$ months, and the site should return to its initial ratios afterwards.

The evaluation of technological efficiency is carried out for the entire profile log straightening zone and involves summation of the actual oil and liquid production for all observation wells. The duration of the profile log straightening effect corresponds to the moment when the actual oil production decreases below the calculated oil production base.

Considering high current water cut at the BS11 production target, where the profile log straightening technology is used, the main method for determining the effect is the method of displacement characteristics. When assessing the profile log straightening technological efficiency, the Sazonov water cut curve is the most commonly used:

$Q_{\text {oil }}=a+b \cdot \operatorname{Ln}\left(Q_{w}\right)$

where $Q_{\text {oil }}, Q_{w}$ cumulative oil and liquid uptakes, respectively, tons / day;

$a, b$ coefficients, which are obtained as a result of statistical processing of factual data.

These coefficients can be analytically determined according to the least-square method:

$$
\begin{aligned}
& a=\frac{\left(\sum_{i} y_{i}\right)\left(\sum_{i}\left(x_{i}^{2}\right)\right)-\left(\sum_{i} x_{i}\right)\left(\sum_{i} x_{i} \cdot y_{i}\right)}{n\left(\sum_{i}\left(x_{i}^{2}\right)\right)-\left(\sum_{i} x_{i}\right)^{2}} \\
& b=\frac{n\left(\sum_{i} x_{i} \cdot y_{i}\right)-\left(\sum_{i} x_{i}\right)\left(\sum_{i} y_{i}\right)}{n\left(\sum_{i}\left(x_{i}^{2}\right)\right)-\left(\sum_{i} x_{i}\right)^{2}}
\end{aligned}
$$

Using the obtained coefficients, $a$ and $b$, we define the theoretical predicted value of the cumulative oil production in the method considered.

In practical work, in addition to the analytical method, the graphical one has become widely used. Based on the production data, it is necessary to construct a prognostic water cut curve on a coordinate plane and a trend line in this zone [36]. Specifying the volume of fluid production, it is possible to determine the increase in oil production due to the technology described above [37; 38]. Figure 2 (compiled by the authors) represents a dependence diagram of the natural logarithm of the cumulative oil production on cumulative fluid production.

The depicted dependence (see Fig. 2) shows that the effect of the above treatment was obtained, since the prognostic curve for cumulative oil production (trend line in the selected straight-line section) lies below the actual curve after the profile log straightening implementation.

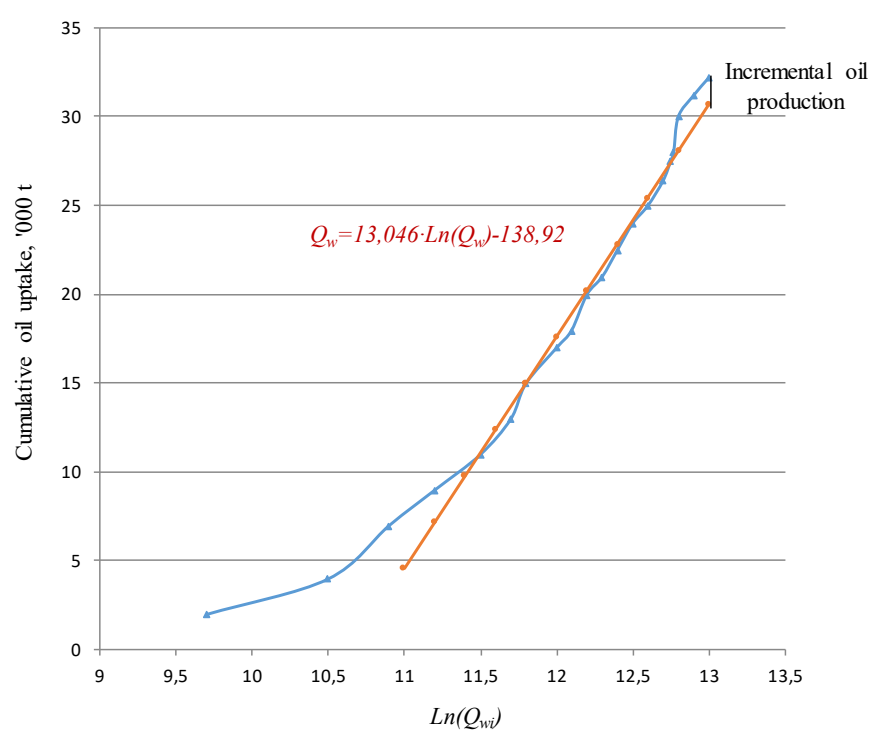

Figure 2: Technological efficiency determination according to the Sazonov method

Let us find the coefficients $a$ and $b$ also using the analytical approach - using the least-square method. For $x_{i}=L$ $n\left(Q_{w i}\right)$ and $y_{i}=Q_{\text {oili }}$ we will denote tabular (production) data. $y_{i}=a+b \cdot x_{i}$ is the straight-line equation approximating the field data before applying the profile log straightening technology. The number of points used to plot the trend line is $n=8$. By formulas (2), (3), we determine the coefficients.

$a=\frac{151,538 \cdot 1172,067-96,81 \cdot 1840,95}{8 \cdot 1172,067-96,81^{2}}=-138,925$

$b=\frac{8 \cdot 1840,95-96,81 \cdot 151,538}{8 \cdot 1172,067-96,810^{2}}=13,046$

Thus, the approximation straight-line equation is as follows: $Q_{\text {oil }}=13,046 \cdot \operatorname{Ln}\left(Q_{w}\right)-138,925$

Then we will calculate the prognostic cumulative oil production according to the equation presented in Figure 2, the duration of the effect was about seven months. 
$Q_{\text {cum.oil }}=13046 \cdot 12,92-138925=29629,32 t$

Now we will estimate the cumulative effect from carrying out measures for the profile log straightening at the Muravlenkovskoye field:

$Q e_{\text {ff.oil }}=32$ 367-29 629,32=2737,68 $t$

Consequently, in case of successful treatment, the incremental oil production of the 7-months effect will be $2,737.68$ tons of oil.

\section{CONCLUSION}

Based on the evidence found, it may be deduced that the profile log straightening not only increases the oil recovery factor, but also dramatically reduces the water production and injection volumes, thereby reducing energy consumption for the well production.

According to all of the afore said, it is arguable that the correct use of technologies for the profile log straightening will allow to redistribute filtration flows and use oil reserves in the non-draining reservoir compartments for displacement. Furthermore, it is necessary to be considerate to selecting wells for the profile log straightening, as inappropriate treatment may result in a decline of oil production and deterioration of the filtration reservoir characteristics.

\section{REFERENCES}

1. Khisamov R.S., Gazizov A.A., Gazizov A.S. (2003). Increase in the coverage of productive layers by impact, VNIIOENG: Moscow, Russia, $568 \mathrm{p}$.

2. Kondrashev A.O., Rogachev M.K., Kondrasheva N.K. (2012). Filtration and microrheological studies of water-insulating polymer compositions. Oil and Gas Business, Volume 6, pp. 80-87.

3. Lake L.W. (2010). Enhanced Oil Recovery. Prentice Hall: NewJersey, 449 p.

4. Mavliev A.R., Rogachev M.K., Mardashov D.V. (2011). Justification of the volume of injection of flow-deflecting compositions into injection wells. Journal of Mining Institute, Volume 189, pp. 182-187.

5. Mardashov, D., Islamov, S., and Nefedov, Y. (2020). Specifics of well killing technology during well service operation in complicated conditions. Periodico Tche Quimica, Volume 17(34), pp. 782-792.

6. Markin A.N., Sukhoverkhov S.V., Brikov A.V. (2016). Oilfield chemistry: Analytical methods, Sakhalin regional printing house: Yuzhno-Sakhalinsk, Russia, 212 p.

7. Norman, C., De Lucia, J., Turner, B. (2006). Improving volumetric sweep efficiency with polymer gels in the Cuyo Basin of Argentina. Proceedings - SPE Symposium on Improved Oil Recovery, 1, pp. 183192. http://doi.org/10.2118/99379-MS

8. Persiancev M.N. (2017). Oil production in the complicated conditions, Nedra-Businesscenter LLC: Moscow, Russia.
9. Raupov I.R., Kondrasheva N.K., Burkhanov R.N. (2014). Method of control over the development of an oil field at the final stage during intraplast water isolation. Vestnik TsKR Rosnedra, Volume 4, pp. 30-35.

10. Raupov, I.R., Korobov, G.Y. (2018). Substantiation and selection of an inhibitor for preventing the formation of asphalt-resin-paraffin deposits. Acta Technica CSAV, Volume 63(1), pp. 537-546.

11. Rogatchev, M.K., Kondrashev, A.O. (2016). Justification of the technology of in-situ water isolation in low-permeable reservoirs. Journal of Mining Institute, Volume 217, pp. 55-60.

12. Sánchez, E., Villamizar, J., Mantilla, G., Rodriguez, J., Roa, M. (2020). Determination of the gelification kinetics of a correction gel of injection profiles by ultraviolet-visible spectroscopy. Journal of Physics: Conference Series, 2020. Volume 1587(1).

13. Kondrashev, A., \& Rogachev, M.K. (2020). Experiments of fluid diversion ability of a new waterproofing polymer solution. Petroleum Exploration and Development, Volume 42(4), pp. 554-559. http://doi. org/10.1016/S1876-3804(15)30049-5

14. Shagiakhmetov, A.M., Podoprigora, D.G., \& Terleev, A.V. (2020). The study of the dependence of the rheological properties of gelforming compositions on the crack opening when modeling their flow on a rotational viscometer. Periodico Tche Quimica, Volume 17(34), pp. 933-939.

15. Shangaraeva L.A., Tananykhin D.S., Sun D.V. (2018). An environmental study on reorganizing the reservoir pressure maintenance system for western Siberia oil fields. Ekoloji, Volume 27, Issue 106, pp. 1175-1180.

16. Strizhnev K.V. (2010). Repair and insulation work in wells: Theory and practice, Nedra: St. Petersburg, Russia, $560 \mathrm{p}$.

17. Sukhikh, A.S., Rogachev, M.K., Kuznetsova, A.N., Maltcev, A.A. (2020). Physical and mathematical modelling of waterflooding low-permeability reservoirs using surfactants. Topical Issues of Rational Use of Natural Resources 2020, Volume 2, pp. 907-913.

18. Lirova B.I. (2008). Analysis of polymer composite materials, Publishing house of the Ural University: Yekaterinburg, Russia, 2008; 187 p.

19. Raupov, I.R., Shagiakhmetov, A.M. (2019). The results of the complex rheological studies of the crosslinked polymer composition and the grounding of its injection volume. International Journal of Civil Engineering and Technology 2019, Volume 10(2), pp. 493-509.

20. Shagiakhmetov, A.M., Raupov, I.R., Terleev, A.V. (2019). Investigation of selective properties of the gel-forming composition for the limitation of water inflow to carbonate reservoirs conditions. International Journal of Civil Engineering and Technology 2019, Volume 10(2), pp. 485-492. 
21. Ibatullin R.R., Khisamutdinov M.R., Gafarov S. K. (2007). New technologies for increasing the coverage of reservoirs by flooding. Oil industry, Volume 7 , pp. 46-49.

22. Pnevskikh A.V., Klimova N. S., Zhuk Zh.V. (2013). Statistical approach to the application of flow-deflecting compositions on the example of the Lyantorskoye field. Oil industry, Volume 2, pp. 70-72.

23. Belonogov E.V., Korovin A.Yu., Yakovlev A.A. (2019). Increasing the pick-up rate by dynamic development of injection wells. Journal of Mining Institute 2019, Volume 238.

24. Kondakov A.P., Gusev S.V., Surnova T.M. (2014). Results of the application of technologies for limiting water inflow into producing wells in conditions of low-permeable reservoirs. Oil industry, 2014. Volume 10, pp. 100-101.

25. Gareev A.A. (2017). Analysis of the effectiveness of intra-layer water insulation technologies with the use of polymer compositions. Bulatov Readings, Volume 2, pp. 124-126.

26. smagilov T.A. (2015). Application of flow-deflecting technologies taking into account the mechanism of well production flooding. Oil industry 2015, Volume 11, pp. 56-59.

27. Nikitin M.N., Petukhov A.V. (2011). Gel-forming composition based on sodium silicate for limiting water inflow in complex-built fractured reservoirs. Oil and gas business 2011. Volume 5, pp. 143-153.

28. Kondrashev A.O., Rogachev M.K., Kondrashev (2014). O.F. Water-insulating polymer composition for low-permeable reservoirs. Oil industry, Volume 4, pp. 63-65.

29. Raupov I.R., Kondrasheva N.K., Raupov R.R. (2016). Development of polymer compositions for intraplastic water isolation of terigennyh reservoirs of oil fields. Oil and gas business, Volume 14, pp. 80-87.

30. Prischepa O.M., Khalimov E.M. (2011). Hard-to-recovery oil: potential, status, and development opportunities. Oil and gas vertical 2011, Volume 5, pp. 24-29.

31. Bylin A.V., Raupov I.R. (2017). Control over the process of oil recovery by in-situ waterproofing. Bulatov readings. Volume 2 , pp. 39-41.
32. Khusainov V. M. (2013). Ways to improve the efficiency of oil deposits development in terrigenous reservoirs at the late stage of development (on the example of the Romashkinskoye field). Problems of improving the efficiency of oil fields development at the late stage. Materials of the International Scientific and Practical Conference. Kazan 2013. pp. 42-46.

33. Shuvalov S.A., Vinokurov V.A., Khlebnikov V. N. (2013). Application of polymer reagents for increasing oil recovery and water isolation. Proceedings of Gubkin Russian State University of Oil and Gas. Volume 4 (273), pp. 98-104.

34. Kadyrov R.R. (2014). Restriction of water inflow in fractured-porous carbonate reservoirs with the use of water-swollen elastomers. Oil industry. Volume 4, pp. 70-72.

35. Raupov I.R. (2012). Automated determination of optical properties of oil for solving geological and field problems. IX International youth oil and gas forum: Abstract. Almaty, pp. 57-59.

36. Yemelyanov, V. A., Nedelkin, A. A., \& Olenev, L. A. (2019). An object-oriented design of expert system software for evaluating the maintenance of lined equipment. Paper presented at the 2019 International Multi-Conference on Industrial Engineering and Modern Technologies, FarEastCon 2019, http://doi. org/doi:10.1109/FarEastCon.2019.8934414

37. Zhukovskyy, V., Zhukovska, N., Vlasyuk, A., \& Safonyk, A. (2019). Method of forensic analysis for compromising carrier-lock algorithm on $3 G$ modem firmware. Paper presented at the 2019 IEEE 2nd Ukraine Conference on Electrical and Computer Engineering, UKRCON 2019 - Proceedings, 1179-1182. http://doi.org/doi:10.1109/UKRCON.2019.8879941

38. Mustafin, A., \& Kantarbayeva, A. (2018). Supply chain modeled as a metabolic pathway. Mathematical Modelling and Analysis, 28(3), 473-491. http:// doi.org/doi:10.3846/mma.2018.028
Paper submitted: 18.03.2021.

Paper accepted: 20.04.2021.

This is an open access article distributed under the CC BY 4.0 terms and conditions. 